Article

\title{
Synthesis, Crystal Structure and Water Vapor Adsorption Properties of a Porous Supramolecular Architecture
}

\author{
Rui Qiao *, Zi-You Zhang and Mei-An Zhu \\ College of Chemistry \& Chemical Engineering, Fuyang Normal University, Fuyang 236041, China; \\ fyzhiyouzhang@126.com (Z.-Y.Z.); zhumeian2017@163.com (M.-A.Z.) \\ * Correspondence: qiaorui@mail.ipc.ac.cn; Tel.: +86-558-2595626 \\ Academic Editor: Helmut Cölfen \\ Received: 23 July 2017; Accepted: 29 September 2017; Published: 2 October 2017
}

\begin{abstract}
A new complex, $\left[\mathrm{Cu}_{4}(\mathrm{HL})_{4}\left(\mathrm{H}_{2} \mathrm{O}\right)_{14}\right]\left(\mathbf{1}, \mathrm{H}_{3} \mathrm{~L} \cdot \mathrm{HCl}=\right.$ 5-((4-carboxypiperidin-1-yl)methyl) isophthalic acid hydrochloride), has been prepared and characterized by single-crystal X-ray diffraction, elemental analysis, IR spectroscopy and powder X-ray diffraction (PXRD). The result of the $X$-ray diffraction analysis reveals that the complex crystallizes in monoclinic, space group $C 2 / c$ and three unique $\mathrm{Cu}(\mathrm{II})$ atoms that are connected by partially deprotonated $\mathrm{HL}^{2-}$ anion to form a cyclic structure. The rich hydrogen bonding and $\pi-\pi$ non-covalent packing interactions extend cyclic units into a three-dimensional (3D) supramolecular polymer. Moreover, the thermogravimetric (TG) analysis and water vapor adsorption property of $\mathbf{1}$ were also discussed.
\end{abstract}

Keywords: $\mathrm{Cu}(\mathrm{II})$ complex; supramolecular architecture; water vapor adsorption

\section{Introduction}

Recently, much progress has been made in the field of metal organic coordination polymers. A large number of novel polymers with intriguing structures and topologies have been constructed by means of deliberate design by researchers, which possess favorable properties such as magnetism, photoluminescence, gas adsorption/separation, and catalysis [1-4]. Generally, the metal-organic polymers are composed of the two fundamental elements of organic ligands and metal ions. Therefore, the nature of ligands and metal ions has a great influence on the structures and properties of polymers [5-7]. In addition, other factors including the solvent system, $\mathrm{pH}$ value, counterions, metal-to-ligand ratio, and reaction temperature can also decide the structures of polymers [8-10]. Furthermore, weak interactions among supramolecular structures such as hydrogen bonding and $\pi-\pi$ stacking can significantly contribute to the construction of a high-dimensional framework [11-13]. In this context, the design of organic ligands is the vital factor for building desirable metal organic coordination polymers [14,15]. Among the devised organic ligands, the multi-N donor and carboxylate organic ligands are most extensively employed to build diverse polymers with novel structures and interesting properties. It should be mentioned that multi-carboxylate organic ligands such as 1,3-benzenedicarboxylate, 1,4-benzenedicarboxylate, 1,3,5-benzenetricarboxylate, and others have been widely used in the assembly of coordination polymers due to the favorable coordination ability for the carboxyl groups [16,17]. In addition to the diverse coordination modes, the carboxyl groups can also act as a hydrogen bonding donor or acceptor, which benefits the formation of high-dimensional supramolecular structures [18]. Based on the diverse coordination modes of the carboxylate ligands, we have designed a series of routes to synthesize a semirigid polycarboxylate ligand-5-((4-carboxypiperidin-1-yl)methyl)isophthalic acid hydrochloride $\left(\mathrm{H}_{3} \mathrm{~L} \cdot \mathrm{HCl}\right)$ in our previous study [19]. Significantly, the organic molecule possesses three carboxyl groups, which may potentially 
show various coordination modes to coordinate with metal ions, benefiting the formation of diverse coordination polymers. Meanwhile, the carboxyl groups can act as hydrogen bond acceptors/donors, depending upon the degree of deprotonation. Furthermore, the ligand includes the flexible $-\mathrm{CH}_{2}-$ group which make the connected carboxyl group flexibly twist in order to meet the coordination requirements of metal centers [19]. In this work, we make a further study to build metal organic coordination polymers based on the multi-carboxylate ligand. Here, we report the syntheses and crystal structure of a new coordination polymer $\left[\mathrm{Cu}_{4}(\mathrm{HL})_{4}\left(\mathrm{H}_{2} \mathrm{O}\right)_{14}\right](\mathbf{1})$ obtained by the reaction of $\mathrm{H}_{3} \mathrm{~L} \cdot \mathrm{HCl}$ with $\mathrm{CuCl}_{2} \cdot 2 \mathrm{H}_{2} \mathrm{O}$.

\section{Results and Discussion}

\subsection{Structural Description of $\left[\mathrm{Cu}_{4}(\mathrm{HL})_{4}\left(\mathrm{H}_{2} \mathrm{O}\right)_{14}\right](\mathbf{1})$}

The compound 1 crystallizes in the monoclinic $C 2 / c$ space group with the asymmetric unit containing three independent $\mathrm{Cu}$ (II) ions with one or a half occupancies, two completely deprotonated $\mathrm{HL}^{2-}$ ligands and seven coordinated water molecules (Figure 1). The central $\mathrm{Cu} 1$ and $\mathrm{Cu} 3$ atoms with half occupancies are six coordinated by carboxylate oxygen atoms from the $\mathrm{HL}^{2-}$ ligand, or coordinated water ligands, forming a distorted octahedral coordination geometry, with $\mathrm{Cu}-\mathrm{O}$ bond distances ranging from 2.005(3) to 2.133(3) $\AA$ (Table 1). The unique Cu2 atom coordinates with two carboxylate oxygen atoms $(\mathrm{O} 6, \mathrm{O} 7)$ from two different $\mathrm{HL}^{2-}$ ligands, and another three oxygen atoms (O3W, O4W, O5W) from three coordinated water ligands, thereby forming a five-coordinated with distorted square-pyramidal coordination geometry. The $\mathrm{HL}^{2-}$ ligands are both employed as a $\mu_{2}$-bridge to link two $\mathrm{Cu}$ (II) atoms with two carboxylate groups by adopting a $\mu_{1}-\eta^{0}: \eta^{1}$-monodentate coordination mode, while the third carboxylate group is deprotonated so as to keep the positive charge balance of the $\mathrm{Cu}$ (II) complex. Four $\mathrm{HL}^{2-}$ ligands link $\mathrm{Cu}$ (II) atoms to form cyclic-tetranuclear $\mathrm{Cu}_{4}\left(\mathrm{HL}^{2-}\right)_{4}$ building units (Figure 1). Meanwhile, the carboxylate moieties can service as hydrogen bonding acceptors that are favorable to benefitting the construction of supramolecular structures. As a result, abundant hydrogen bonds are present among coordinated water molecules and carboxylate groups, as exhibited in Table 2. The cyclic-tetranuclear $\mathrm{Cu}_{4}\left(\mathrm{HL}^{2-}\right)_{4}$ units were a bridge to a one-dimensional (1D) chain by hydrogen bonding interactions $\left(\mathrm{O}(5 \mathrm{~W}) \cdots \mathrm{O}(5)^{\mathrm{g}} 2.525(4) \AA, \mathrm{O}(5 \mathrm{~W})-\mathrm{H}(5 \mathrm{X}) \cdots \mathrm{O}(5) 153^{\circ} ; \mathrm{O}(5 \mathrm{~W}) \cdots \mathrm{O}(5 \mathrm{~W})^{\mathrm{g}} 3.047(4) \AA\right.$, $\mathrm{O}(5 \mathrm{~W})-\mathrm{H}(5 \mathrm{Y}) \cdots \mathrm{O}(5 \mathrm{~W})^{\mathrm{g}} 114^{\circ} ; \mathrm{O}(5 \mathrm{~W}) \cdots \mathrm{O}(8)^{\mathrm{g}} 2.768(4) \AA, \mathrm{O}(5 \mathrm{~W})-\mathrm{H}(5 \mathrm{Y}) \cdots \mathrm{O}(8) 125^{\circ}$ ) (Figure 2). Particularly, the central benzene plane of ligands between the adjacent 1D chains are parallel and separated by a centroid-centroid distance of $3.57 \AA$, indicating the presence of strong $\pi-\pi$ stacking interactions [20]. The adjacent 1D chains also have the hydrogen bonds $\left(\mathrm{O}(4) \cdots \mathrm{O}(7 \mathrm{~W})^{\mathrm{f}}\right.$ 3.298(4) $\AA, \mathrm{O}(4)-\mathrm{H}(4 \mathrm{C}) \cdots \mathrm{O}(7 \mathrm{~W})$ $\left.153^{\circ} ; \mathrm{N}(2) \cdots \mathrm{O}(4)^{\mathrm{c}} 2.772(4) \AA, \mathrm{N}(2)-\mathrm{H}(2) \cdots \mathrm{O}(4)^{\mathrm{c}} 170^{\circ}\right)$ that were connected to the two-dimensional (2D) layer structure (Figure 3). Furthermore, the adjacent layers pack together via extensive $\mathrm{O}-\mathrm{H} \cdots \mathrm{O}$ and $\mathrm{C}-\mathrm{H} \cdots \mathrm{O}$ hydrogen bond interactions $\left(\mathrm{O}(3 \mathrm{~W}) \cdots \mathrm{O}(2)^{\mathrm{a}}{ }^{\mathrm{a}}\right.$, 2.954(4) $\AA, \mathrm{O}(3 \mathrm{~W})-\mathrm{H}(3 \mathrm{Y}) \cdots \mathrm{O}(2) 125^{\circ}$; $\mathrm{C}(24) \cdots \mathrm{O}(12)^{\mathrm{d}} 3.383(5) \AA, \mathrm{C}(24)-\mathrm{H}(24 \mathrm{~A}) \cdots \mathrm{O}(12) 163^{\circ} ; \mathrm{C}(24) \cdots \mathrm{O}(12)^{\mathrm{d}} 3.383(5) \AA, \mathrm{C}(24)-\mathrm{H}(24 \mathrm{~A}) \cdots \mathrm{O}(12) 163^{\circ}$; $\mathrm{C}(3) \cdots \mathrm{O}(2 \mathrm{~W})^{\mathrm{e}} 3.142(5) \AA, \quad \mathrm{C}(3)-\mathrm{H}(3) \cdots \mathrm{O}(2 \mathrm{~W}) 145^{\circ} ; \mathrm{N}(1) \cdots \mathrm{O}(8)^{\mathrm{a}}$ 2.787(4) $\AA, \mathrm{N}(1)-\mathrm{H}(1) \cdots \mathrm{O}(8) \quad 166^{\circ}$; $\left.\mathrm{C}(5) \cdots \mathrm{O}(2 \mathrm{~W})^{\mathrm{e}} 3.063(5) \AA, \mathrm{C}(5)-\mathrm{H}(5 \mathrm{~B}) \cdots \mathrm{O}(2 \mathrm{~W})^{\mathrm{d}} 141^{\circ}\right)$, generating a 3D supramolecular framework, as shown in Figure 4 (Table 2). There also exist strong $\pi-\pi$ stacking interactions with a centroid-centroid distance of $3.40 \AA$ for the central benzene plane of $\mathrm{HL}^{2-}$ ligands. It should be noted that the coordinated $\mathrm{H}_{2} \mathrm{O}$ molecules occupy the voids between the 3D supramolecular architecture, forming a 3D supra-molecular framework by hydrogen bonding and strong $\pi-\pi$ stacking interactions, which contributes to the stabilization of the crystal packing of the adjacent 1D chain (Figure 5). PLATON [21] analysis shows that the structure of 1 consists of voids of $2286.4 \AA^{3}$ that represent $28.5 \%$ per unit cell volume of $8018.0 \AA^{3}$ upon removal of the coordinated water molecules. 


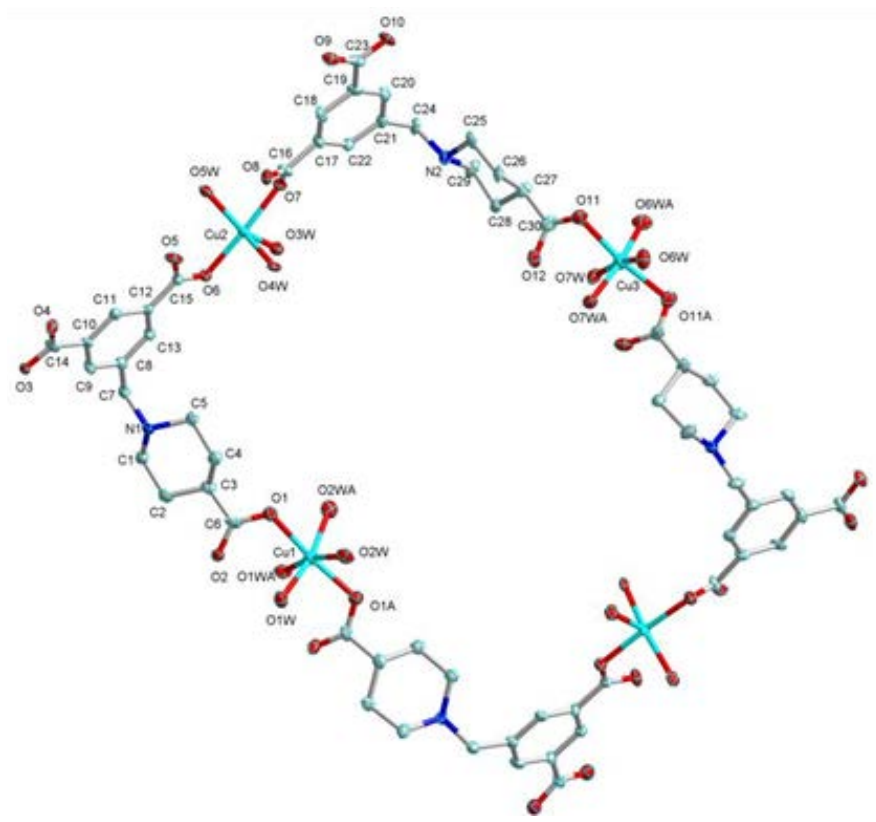

Figure 1. The coordination environment of $\mathrm{Cu}(\mathrm{II})$ in complex 1 with ellipsoids drawn at $30 \%$ probability level (Symmetry codes: (A) $1-x, y, 5 / 2-z$ ).

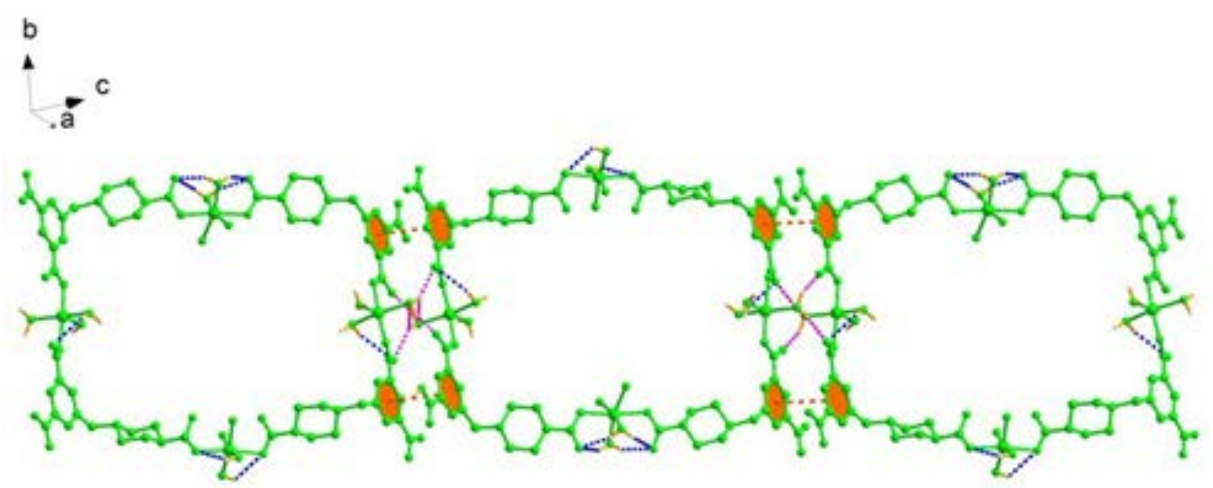

Figure 2. The packing diagram built from a $1 \mathrm{D}$ chain by rich hydrogen bonds and $\pi-\pi$ stacking interaction.

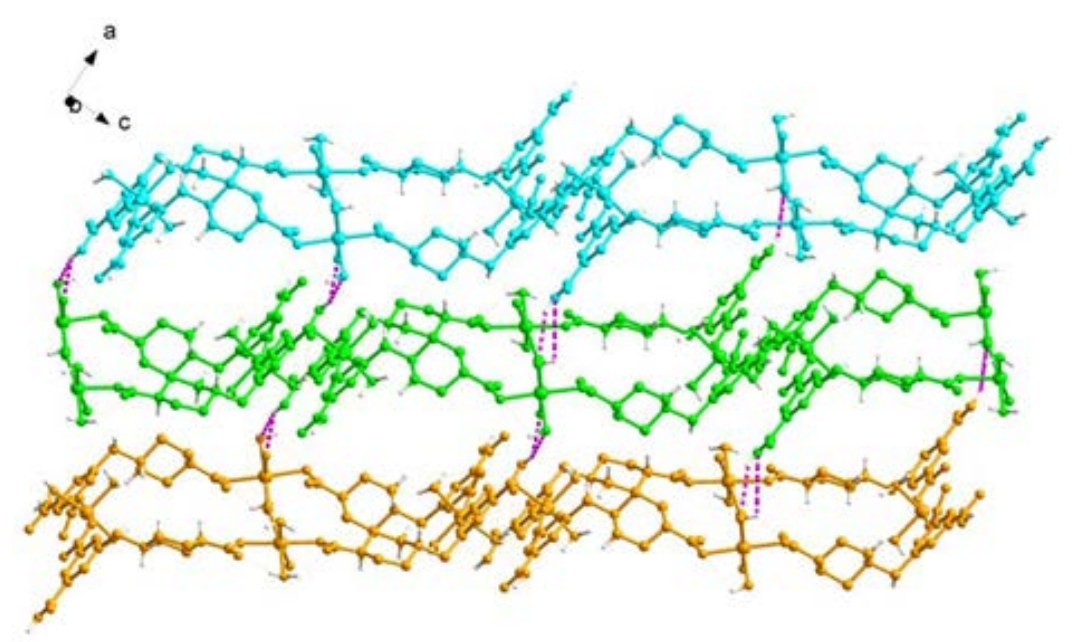

Figure 3. The 2D layer structure linked by rich hydrogen bond interaction. 


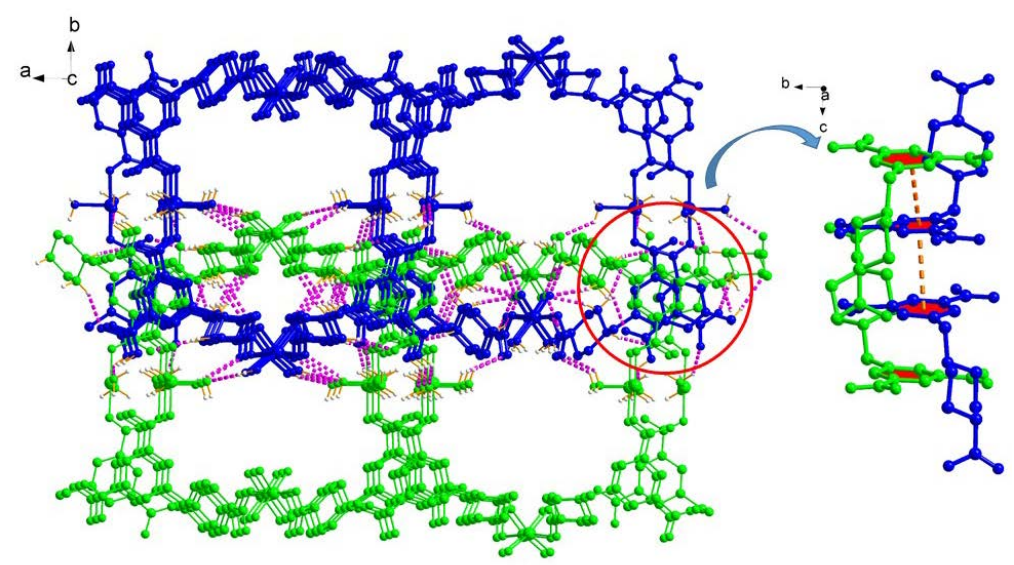

Figure 4. The 3D framework of 1 packed by hydrogen bonds and $\pi-\pi$ stacking interactions.

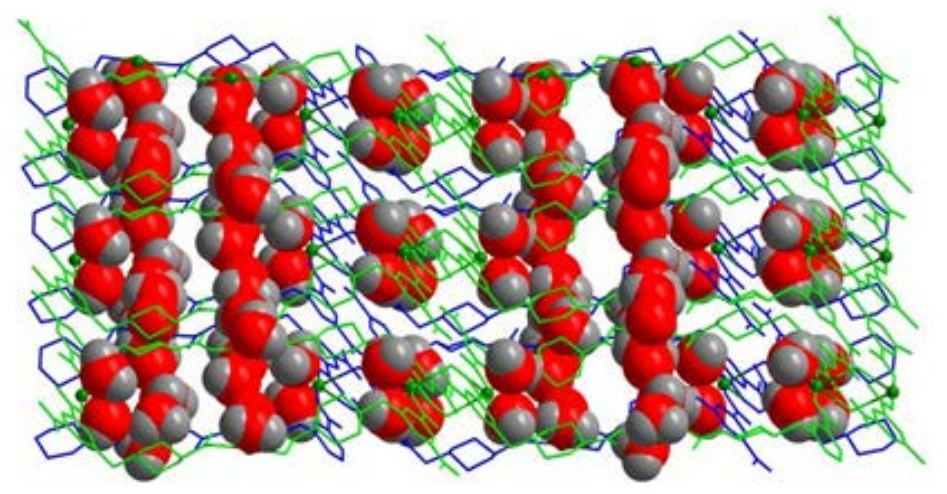

Figure 5. 3D supramolecular architecture with voids occupied by coordinated water molecules highlighted in space-filling.

Table 1. Selected bond lengths $(\AA)$ and bond angles $\left(^{\circ}\right)$ for $\mathbf{1}$.

\begin{tabular}{|c|c|c|c|}
\hline Bond & $d$ & Bond & $d$ \\
\hline $\mathrm{Cu}(1)-\mathrm{O}(1 \mathrm{~W})$ & $2.003(3)$ & $\mathrm{Cu}(1)-\mathrm{O}(1)$ & $2.053(3)$ \\
\hline $\mathrm{Cu}(1)-\mathrm{O}(2 \mathrm{~W})$ & $2.048(3)$ & $\mathrm{Cu}(2)-\mathrm{O}(3 \mathrm{~W})$ & $2.066(3)$ \\
\hline $\mathrm{Cu}(2)-\mathrm{O}(4 \mathrm{~W})$ & $2.003(3)$ & $\mathrm{Cu}(2)-\mathrm{O}(5 \mathrm{~W})$ & $2.119(3)$ \\
\hline $\mathrm{Cu}(2)-\mathrm{O}(6)$ & $1.979(3)$ & $\mathrm{Cu}(2)-\mathrm{O}(7)$ & $2.013(3)$ \\
\hline $\mathrm{Cu}(3)-\mathrm{O}(6 \mathrm{~W})$ & $2.046(3)$ & $\mathrm{Cu}(3)-\mathrm{O}(7 \mathrm{~W})$ & $2.009(3)$ \\
\hline $\mathrm{Cu}(3)-\mathrm{O}(11)$ & $2.131(3)$ & - & - \\
\hline Angle & $\omega$ & Angle & $\omega$ \\
\hline $\mathrm{O}(1)-\mathrm{Cu}(1)-\mathrm{O}(1 \mathrm{~W})$ & $94.90(13)$ & $\mathrm{O}(1)-\mathrm{Cu}(1)-\mathrm{O}(2 \mathrm{~W})$ & $103.39(13)$ \\
\hline $\mathrm{O}(1)-\mathrm{Cu}(1)-\mathrm{O}(1)^{\mathrm{i}}$ & $174.45(17)$ & $\mathrm{O}(1)-\mathrm{Cu}(1)-\mathrm{O}(1 \mathrm{~W})^{\mathrm{i}}$ & $88.99(13)$ \\
\hline $\mathrm{O}(1)-\mathrm{Cu}(1)-\mathrm{O}(2 \mathrm{~W})^{\mathrm{i}}$ & $73.05(12)$ & $\mathrm{O}(1 \mathrm{~W})-\mathrm{Cu}(1)-\mathrm{O}(2 \mathrm{~W})^{\mathrm{i}}$ & $73.00(11)$ \\
\hline $\mathrm{O}(1 \mathrm{~W})-\mathrm{Cu}(1)-\mathrm{O}(2 \mathrm{~W})$ & $83.85(12)$ & $\mathrm{O}(1 \mathrm{~W})-\mathrm{Cu}(1)-\mathrm{O}(1 \mathrm{~W})^{\mathrm{i}}$ & $91.16(18)$ \\
\hline $\mathrm{O}(1 \mathrm{~W})-\mathrm{Cu}(1)-\mathrm{O}(2 \mathrm{~W})^{\mathrm{i}}$ & $166.98(12)$ & $\mathrm{O}(2 \mathrm{~W})-\mathrm{Cu}(1)-\mathrm{O}(2 \mathrm{~W})^{\mathrm{i}}$ & $103.45(17)$ \\
\hline $\mathrm{O}(3 \mathrm{~W})-\mathrm{Cu}(2)-\mathrm{O}(5 \mathrm{~W})$ & $97.37(12)$ & $\mathrm{O}(3 \mathrm{~W})-\mathrm{Cu}(2)-\mathrm{O}(6)$ & $90.65(11)$ \\
\hline $\mathrm{O}(3 \mathrm{~W})-\mathrm{Cu}(2)-\mathrm{O}(7)$ & $88.08(11)$ & $\mathrm{O}(4 \mathrm{~W})-\mathrm{Cu}(2)-\mathrm{O}(7)$ & $94.05(11)$ \\
\hline $\mathrm{O}(4 \mathrm{~W})-\mathrm{Cu}(2)-\mathrm{O}(5 \mathrm{~W})$ & $169.00(11)$ & $\mathrm{O}(4 \mathrm{~W})-\mathrm{Cu}(2)-\mathrm{O}(6)$ & $91.45(11)$ \\
\hline $\mathrm{O}(6 \mathrm{~W})-\mathrm{Cu}(3)-\mathrm{O}(7 \mathrm{~W})$ & $74.90(12)$ & $\mathrm{O}(6 \mathrm{~W})-\mathrm{Cu}(3)-\mathrm{O}(11)$ & $88.51(14)$ \\
\hline $\mathrm{O}(6 \mathrm{~W})-\mathrm{Cu}(3)-\mathrm{O}(7 \mathrm{~W}){ }^{\mathrm{i}}$ & $165.99(12)$ & $\mathrm{O}(6 \mathrm{~W})-\mathrm{Cu}(3)-\mathrm{O}(6 \mathrm{~W})^{\mathrm{i}}$ & $119.1(2)$ \\
\hline $\mathrm{O}(6 \mathrm{~W})-\mathrm{Cu}(3)-\mathrm{O}(11)^{\mathrm{i}}$ & $87.35(11)$ & $\mathrm{O}(7 \mathrm{~W})-\mathrm{Cu}(3)-\mathrm{O}(11)$ & $96.51(13)$ \\
\hline $\mathrm{O}(7 \mathrm{~W})-\mathrm{Cu}(3)-\mathrm{O}(7 \mathrm{~W})^{\mathrm{i}}$ & 91.36(19) & $\mathrm{O}(7 \mathrm{~W})-\mathrm{Cu}(3)-\mathrm{O}(11)^{\mathrm{i}}$ & $89.06(13)$ \\
\hline $\mathrm{O}(6 \mathrm{~W})^{\mathrm{i}}-\mathrm{Cu}(3)-\mathrm{O}(11)$ & $87.46(14)$ & $\mathrm{O}(11)-\mathrm{Cu}(3)-\mathrm{O}(11)^{\mathrm{i}}$ & $172.04(19)$ \\
\hline
\end{tabular}

Symmetry codes: (i) $1-x, y, 5 / 2-z$. 
Table 2. Hydrogen bond lengths (å) and bond angles $\left(^{\circ}\right)$ for $\left[\mathrm{Cu}_{4}(\mathrm{HL})_{4}\left(\mathrm{H}_{2} \mathrm{O}\right)_{14}\right]_{\mathrm{n}}$.

\begin{tabular}{ccccc}
\hline $\mathbf{D}-\mathbf{H} \cdots \mathbf{A}$ & $\mathbf{d}(\mathbf{D}-\mathbf{H})$ & $\mathbf{d}(\mathbf{H} \cdots \mathbf{A})$ & $\mathbf{d}(\mathbf{D} \cdots \mathbf{A})$ & $\angle \mathbf{D H A}$ \\
\hline $\mathrm{N}(1)-\mathrm{H}(1) \cdots \mathrm{O}(8)^{\mathrm{a}}$ & 0.91 & 1.90 & $2.787(4)$ & 166 \\
$\mathrm{O}(1 \mathrm{~W})-\mathrm{H}(1 \mathrm{X}) \cdots \mathrm{O}(2)$ & 0.85 & 2.05 & $2.838(4)$ & 154 \\
$\mathrm{O}(1 \mathrm{~W})-\mathrm{H}(1 \mathrm{Y}) \cdots \mathrm{O}(2)^{\mathrm{b}}$ & 0.85 & 2.08 & $2.790(4)$ & 140 \\
$\mathrm{~N}(2)-\mathrm{H}(2) \cdots \mathrm{O}(4)^{\mathrm{c}}$ & 0.91 & 1.87 & $2.772(4)$ & 170 \\
$\mathrm{O}(3 \mathrm{~W})-\mathrm{H}(3 \mathrm{X}) \cdots \mathrm{O}(11)^{\mathrm{d}}$ & 0.80 & 2.36 & $2.722(4)$ & 114 \\
$\mathrm{O}(3 \mathrm{~W})-\mathrm{H}(3 \mathrm{Y}) \cdots \mathrm{O}(2)^{\mathrm{e}}$ & 0.88 & 2.36 & $2.959(4)$ & 125 \\
$\mathrm{O}(4)-\mathrm{H}(4 \mathrm{C}) \cdots \mathrm{O}(7 \mathrm{~W})^{\mathrm{f}}$ & 0.96 & 2.49 & $3.298(4)$ & 142 \\
$\mathrm{O}(4 \mathrm{~W})-\mathrm{H}(4 \mathrm{X}) \cdots \mathrm{O}(8)$ & 0.96 & 2.51 & $3.261(4)$ & 135 \\
$\mathrm{O}(4 W)-\mathrm{H}(4 \mathrm{Y}) \cdots \mathrm{O}(3)^{\mathrm{c}}$ & 0.96 & 1.85 & $2.667(4)$ & 141 \\
$\mathrm{O}(5 W)-\mathrm{H}(5 \mathrm{X}) \cdots \mathrm{O}(5)^{\mathrm{g}}$ & 0.96 & 1.63 & $2.525(4)$ & 153 \\
$\mathrm{O}(5 \mathrm{~W})-\mathrm{H}(5 \mathrm{Y}) \cdots \mathrm{O}(5 \mathrm{~W})^{\mathrm{g}}$ & 0.96 & 2.53 & $3.047(4)$ & 114 \\
$\mathrm{O}(5 \mathrm{~W})-\mathrm{H}(5 \mathrm{Y}) \cdots \mathrm{O}(8)^{\mathrm{g}}$ & 0.96 & 2.10 & $2.768(4)$ & 125 \\
$\mathrm{O}(6 \mathrm{~W})-\mathrm{H}(6 \mathrm{Y}) \cdots \mathrm{O}(3 \mathrm{~W})^{\mathrm{h}}$ & 0.87 & 2.47 & $3.336(4)$ & 174 \\
$\mathrm{C}(3)-\mathrm{H}(3) \cdots \mathrm{O}(2 \mathrm{~W})^{\mathrm{e}}$ & 0.98 & 2.29 & $3.142(5)$ & 145 \\
$\mathrm{C}(5)-\mathrm{H}(5 \mathrm{~A}) \cdots \mathrm{O}(9)^{\mathrm{a}}$ & 0.97 & 2.48 & $3.309(5)$ & 143 \\
$\mathrm{C}(5)-\mathrm{H}(5 \mathrm{~B}) \cdots \mathrm{O}(2 W)^{\mathrm{e}}$ & 0.97 & 2.25 & $3.063(5)$ & 141 \\
$\mathrm{C}(24)-\mathrm{H}(24 \mathrm{~A}) \cdots \mathrm{O}(12)^{\mathrm{d}}$ & 0.97 & 2.44 & $3.383(5)$ & 163 \\
$\mathrm{C}(25)-\mathrm{H}(25 \mathrm{~A}) \cdots \mathrm{O}(5)^{\mathrm{c}}$ & 0.97 & 2.49 & $3.318(5)$ & 142 \\
\hline
\end{tabular}

Symmetry codes: (a) $1 / 2-x,-1 / 2+y, 3 / 2-z$; (b) $1-x, y, 5 / 2-z$; (c) $1 / 2-x, 1 / 2+y, 3 / 2-z$; (d) $x, 1-y,-1 / 2+z$; (e) $x,-y,-1 / 2+z$; (f) $-1 / 2+x, 1 / 2-y,-1 / 2+z$; (g) $1 / 2-x, 1 / 2-y, 1-z$; (h) $1-x, 1-y, 2-z$.

\subsection{Thermal Analysis and Powder X-ray Diffraction Analysis}

The thermogravimetric analysis was carried out in order to ascertain the compositional stability of the supramolecular architecture of $\mathbf{1}$, and the result is shown in Figure 6. From the thermogravimetric analysis curves, a weight loss of $13.66 \%$ was observed for $\mathbf{1}$ in the temperature range of $105 \sim 185^{\circ} \mathrm{C}$, due to the loss of water molecules (calcd. 14.05\%); the residue is stable up to about $465{ }^{\circ} \mathrm{C}$. The crystalline phase-purity was confirmed by the powder XRD experiment, and Figure 7 shows the crystalline phase-purity of $\mathbf{1}$, because of the consistency between the as-synthesized sample and the corresponding simulated one.

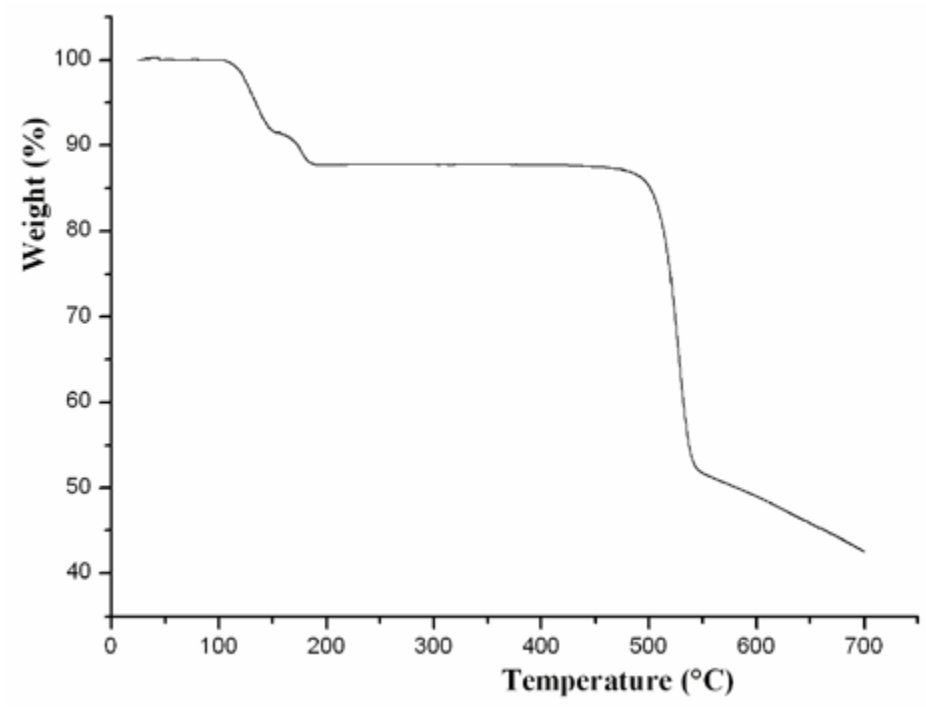

Figure 6. Thermal analysis curve of the complex $\mathbf{1 .}$ 


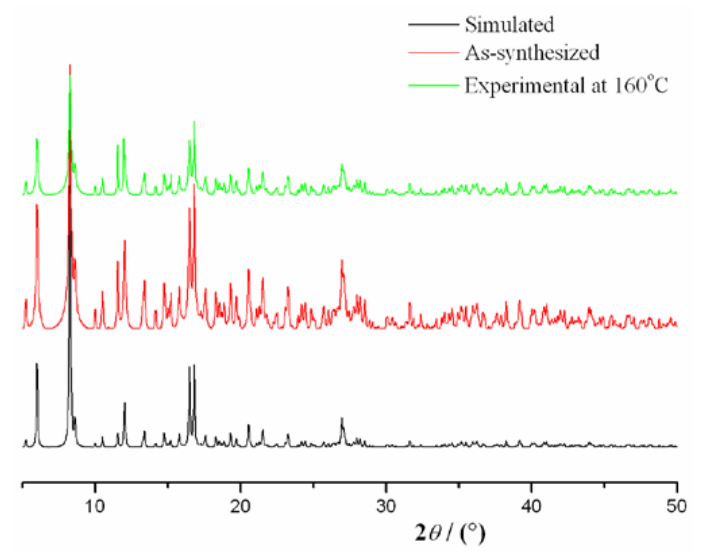

Figure 7. Powder X-ray diffraction patterns of the complex 1 at varied temperatures.

\subsection{Sorption Property of Complex 1}

The structural analysis of $\mathbf{1}$ shows that the carboxyl groups exhibit three different forms as follows: deprotonated to be anion and participate in coordination, or balance the positive charges of $\mathrm{Cu}$ (II) ions by deprotonation, thus exhibiting versatile coordination modes. As mentioned above, water ligands and the carboxyl groups can act as a hydrogen bonding donor or acceptor, and thus there exist rich hydrogen bonding weak interactions among supramolecular structures as exhibited in Figure 2. As shown in the structural analysis, the total void value of $\mathbf{1}$ is estimated to be $28.5 \%$ of the total crystal volume, which is occupied by coordination water ligands, thus a rich hydrogen bonding interaction exists in the supramolecular architecture. In this sense, the backbone of $\mathbf{1}$ shows favorable hydrophilic properties due to the hydrogen bonding interaction. In order to test the hydrophilic property of the supramolecular architecture, water vapor adsorption was carried out in this experiment. TGA and PXRD measurements have been carried out to ascertain the thermal stability of the complex for sorption property investigation. After heating 1 at $160{ }^{\circ} \mathrm{C}$ for $24 \mathrm{~h}$ in a vacuum, the coordinated water molecule was removed. The PXRD pattern shows that the framework of dehydrated samples of $\mathbf{1}^{\prime}$ is retained because of the consistency of the PXRD pattern between the experimental pattern and the dehydrated pattern (Figure 7). Taking into consideration that this coordination polymer framework may have hydrophilic abilities due to the existence of rich hydrogen bonding, a water vapor adsorption experiment was carried out for the dehydrated samples of $\mathbf{1}^{\prime}$ to verify the hydrophilic ability; water vapor adsorption profiles are shown in Figure 8 . The $\mathrm{H}_{2} \mathrm{O}$ vapor adsorption isotherm at $298 \mathrm{~K}$ of $\mathbf{1}^{\prime}$ shows great uptake in the pressure region of $0 \sim 0.25 \mathrm{~atm}$, which then gradually increases (Figure 8). The adsorption value of the $\mathrm{H}_{2} \mathrm{O}$ uptake at $1.0 \mathrm{~atm}$ is $145.39 \mathrm{~cm}^{3} \cdot \mathrm{g}^{-1}$, corresponding to $5.71 \mathrm{H}_{2} \mathrm{O}$ molecules per formula unit. However, the desorption isotherm is not well consistent with the adsorption isotherm, showing a large hysteresis loop with incomplete desorption. This phenomenon may be attributed to the hydrogen bond interactions between water molecules and hydrophilic channels [22].

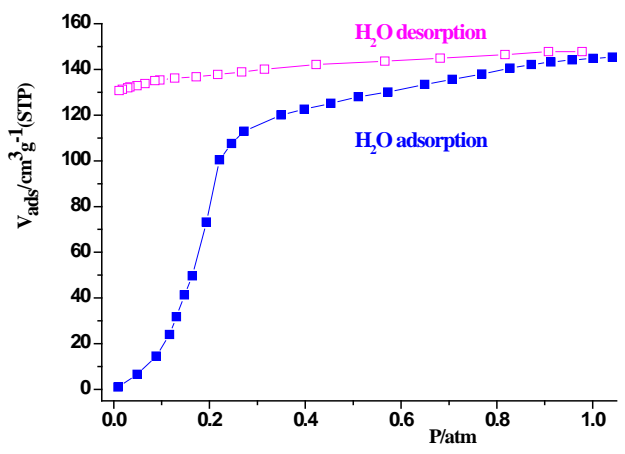

Figure 8. $\mathrm{H}_{2} \mathrm{O}$ adsorption isotherm at $298 \mathrm{~K}$ for $\mathbf{1}^{\prime}$ : filled shape, adsorption; open shape, desorption. 


\section{Experimental Section}

\subsection{Materials and Instrumentation}

All reagents were of reagent grade and used as purchased from commercial sources without further purification. The $\mathrm{H}_{3} \mathrm{~L} \cdot \mathrm{HCl}$ ligand was synthesized according to Scheme 1. Elemental analyses were performed on a Perkin-Elmer 240C Elemental Analyzer (PerkinElmer, Waltham, MA, USA). Infrared spectra were collected from single crystals of the compounds using a Bruker Vector 22 FT-IR spectrophotometer (Instrument Inc., Karlsruhe, Germany) with KBr pellets. Thermogravimetric analyses (TGA) were performed on a simultaneous SDT 2960 thermal analyzer (Thermal Analysis Instrument Inc., New Castle, DE, USA) under nitrogen at a heating rate of $10{ }^{\circ} \mathrm{C} / \mathrm{min}$. Power $X$-ray diffraction (PXRD) patterns were measured on a Shimadzu XRD-6000 X-ray diffractometer (Shimadzu Corporation, Kyoto, Japan) with $\mathrm{CuK \alpha}(\lambda=1.5418 \AA)$ radiation at room temperature. Water $\left(\mathrm{H}_{2} \mathrm{O}\right)$ vapor sorption experiments were carried out on an Autosorb-iQ gas sorption instrument in Quantachrome Instruments U.S (Quantachrome, Delray Beach, FL, USA). The sample was activated by using the "outgas" function of the surface area analyzer (Quantachrome, Delray Beach, FL, USA) for $24 \mathrm{~h}$ at $160^{\circ} \mathrm{C}$.

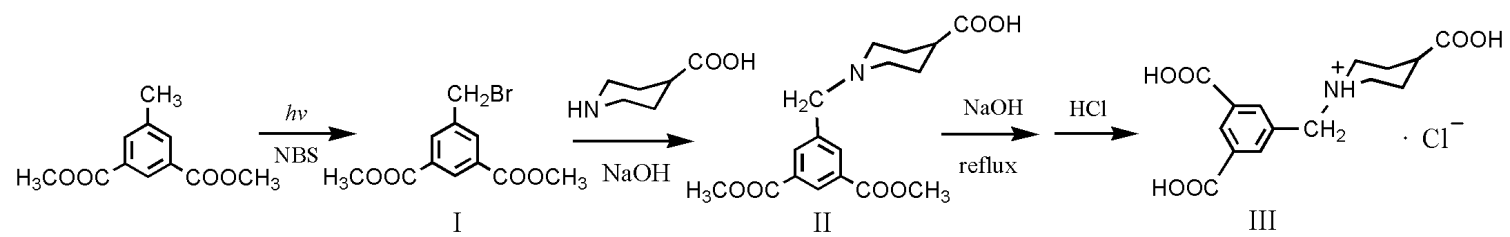

Scheme 1. Synthesis route for ligand $\mathrm{H}_{3} \mathrm{~L} \cdot \mathrm{HCl}$.

\subsection{Synthesis of Dimethyl 5-(Bromomethyl)isophthalate (I)}

A mixture of dimethyl 5-methylisophthalate ( $2.08 \mathrm{~g}, 0.01 \mathrm{~mol})$, N-bromosuccinimide ( $3.56 \mathrm{~g}, 0.02 \mathrm{~mol})$ and benzoyl peroxide $(0.24 \mathrm{~g}, 0.001 \mathrm{~mol})$ in $\mathrm{CCl}_{4}(50 \mathrm{~mL})$ was prepared and heated at $85{ }^{\circ} \mathrm{C}$ under reflux for $2 \mathrm{~h}$. The reaction mixture was then filtered through Celite and the filtrate was concentrated to obtain white power. The residue was subjected to column chromatography (10-40\% EtOAc in hexane) to yield colorless solid $(2.48 \mathrm{~g}, 0.008 \mathrm{mmol})$. Yield: $86 \%$ based on dimethyl 5-methylisophthalate, m.p.: $139 \sim 140{ }^{\circ} \mathrm{C}$. ESI-MS, m/z: $287.25[\mathrm{M}]^{+}$. Anal. Calcd. (\%) for $\mathrm{C}_{11} \mathrm{H}_{11} \mathrm{BrO}_{4}: \mathrm{C}, 46.02 ; \mathrm{H}, 3.86$. Found (\%): $\mathrm{C}, 46.32 ; \mathrm{H}, 3.65 .{ }^{1} \mathrm{H} \mathrm{NMR}\left(\mathrm{CDCl}_{3}, 400 \mathrm{MHz}\right), \delta: 4.08\left(\mathrm{~s}, 6 \mathrm{H}, \mathrm{OCH}_{3}\right), 4.58\left(\mathrm{~s}, 2 \mathrm{H}, \mathrm{CH}_{2} \mathrm{Br}\right), 8.32\left(\mathrm{~s}, 2 \mathrm{H}_{\mathrm{ar}}\right)$, $8.75\left(\mathrm{~s}, 1 \mathrm{H}_{\mathrm{ar}}\right.$ ). IR (KBr pellet, $\left.\mathrm{cm}^{-1}\right)$ : $3424(\mathrm{w}), 3072(\mathrm{w}), 2952(\mathrm{~m}), 1720(\mathrm{vs}), 1602(\mathrm{~m}), 1456(\mathrm{~s}), 1434$ (s), 1275 (s), 1244 (vs), 1337 (s), 1126 (s), 1105 (s), 1000 (s), 925 (s), 892 (w), 865 (m), 757 (vs), 722 (m), 693 (s), $623(\mathrm{~s}), 571(\mathrm{~m})$.

\subsection{Synthesis of 1-(3,5-bis(Methoxycarbonyl)benzyl)piperidine-4-carboxylic Acid (II)}

The mixed solution of piperidine-4-carboxylic acid $(1.29 \mathrm{~g}, 0.01 \mathrm{~mol})$ and $\mathrm{NaOH}(0.8 \mathrm{~g}, 0.02 \mathrm{~mol})$ in DMF $(15 \mathrm{~mL})$ reacted for $1 \mathrm{~h}$ at room temperature. The reactant was added dropwise to a solution of 5-(bromomethyl)isophthalate $(2.87 \mathrm{~g}, 0.01 \mathrm{~mol})$ in $\mathrm{N}, \mathrm{N}$-dimethylformamide (DMF, $20 \mathrm{~mL}$ ) with stirring, and the mixture was heated at $80^{\circ} \mathrm{C}$ for $1 \mathrm{~h}$. When the solution was cooled to room temperature, the solution was poured into water $(100 \mathrm{~mL})$ and white solid was obtained and separated by filtration with a yield of $82 \%$ based on piperidine-4-carboxylic acid. Anal. Calcd. (\%) for $\mathrm{C}_{17} \mathrm{H}_{21} \mathrm{NO}_{6}$ : $\mathrm{C}, 60.89$; $\mathrm{H}, 6.31 ; \mathrm{N}, 4.18$. Found (\%): C, 60.31; H, 6.61; N, 3.91. IR (KBr pellet, $\left.\mathrm{cm}^{-1}\right)$ : $3442(\mathrm{w}), 3093(\mathrm{w})$, $2958(\mathrm{~m}), 1735$ (vs), $1712(\mathrm{~s}), 1613(\mathrm{~m}), 1459$ (s), 1441 (m), 1269(m), 1248(s), 1338(m), 1128 (s), $1112(\mathrm{~m})$, 998(s), $927(\mathrm{~s}), 894(\mathrm{w}), 864(\mathrm{~m}), 758(\mathrm{~s}), 726(\mathrm{~m}), 696(\mathrm{~m}), 625(\mathrm{~m}), 568(\mathrm{~m})$. 


\subsection{Synthesis of 5-((4-Carboxypiperidin-1-yl)methyl)isophthalic Acid Hydrochloride (III, $\left.\mathrm{H}_{3} \mathrm{~L} \cdot \mathrm{HCl}\right)$}

Hydrolysis of the 1-(3,5-bis(methoxycarbonyl)benzyl)piperidine-4-carboxylic acid was accomplished by stirring the solid with 10 equiv of $\mathrm{NaOH}$ in a mixture of EtOH/water $1: 1 \mathrm{kept}$ at $100{ }^{\circ} \mathrm{C}$ for $24 \mathrm{~h}$ followed by acidification using $1 \mathrm{~N} \mathrm{HCl}$, extraction in EtOAc, drying over $\mathrm{Na}_{2} \mathrm{SO}_{4}$, and standing for crystallization (white solid, 80\% yield). Anal. Calcd. (\%) for $\mathrm{C}_{15} \mathrm{H}_{18} \mathrm{~N}_{4} \mathrm{O}_{6} \mathrm{Cl}: \mathrm{C}, 52.41 ; \mathrm{H}, 5.28 ; \mathrm{N}, 4.07$. Found (\%): C, 52.71; H, 5.03; N, 4.23. IR (KBr pellet, $\left.\mathrm{cm}^{-1}\right)$ : $3423(\mathrm{~m}), 3079(\mathrm{~m}), 2943(\mathrm{~m}), 1727$ (vs), $1609(\mathrm{~m}), 1463(\mathrm{~m}), 1396(\mathrm{~m}), 1326(\mathrm{~m}), 1291(\mathrm{~m}), 1240(\mathrm{~m}), 1225(\mathrm{~m}), 1199(\mathrm{~s}), 1142(\mathrm{w}), 1059(\mathrm{~m}), 973$ (w), $917(\mathrm{~m}), 758(\mathrm{~s}), 677(\mathrm{~m}), 666(\mathrm{~m})$.

\subsection{Synthesis of Complex $\left[\mathrm{Cu}{ }_{4}(\mathrm{HL})_{4}\left(\mathrm{H}_{2} \mathrm{O}\right)_{14}\right](\mathbf{1})$}

A mixture containing $\mathrm{H}_{3} \mathrm{~L} \cdot \mathrm{HCl}(34.3 \mathrm{mg}, 0.1 \mathrm{mmol}), \mathrm{CuCl}_{2} \cdot 2 \mathrm{H}_{2} \mathrm{O}(0.1 \mathrm{mmol}, 17.0 \mathrm{mg})$ and $\mathrm{NaOH}$ ( $8.0 \mathrm{mg}, 0.2 \mathrm{mmol}$ ) in $10 \mathrm{~mL} \mathrm{H}_{2} \mathrm{O}$ was sealed in a Teflon-lined stainless-steel autoclave and heated under autogenous pressure to $100{ }^{\circ} \mathrm{C}$ for $72 \mathrm{~h}$ to produce a blue solution. The reaction solution was filtered into a glass beaker sealed with porous preservative film, and filtrate was allowed to slowly evaporate at room temperature. After about $3-4$ weeks, blue block crystals were obtained in $65 \%$ yield by washing with water and ethanol several times. Anal. Calcd for $\mathrm{C}_{60} \mathrm{H}_{88} \mathrm{~N}_{4} \mathrm{O}_{38} \mathrm{Cu}_{4}$ : C, 41.02; $\mathrm{H}, 5.36$; N, 3.24\%. Found: C, 40.56; H, 5.35; N, 2.92\%. IR (KBr pellet, $\left.\mathrm{cm}^{-1}\right)$ : 3630-2962 (m, br), 2952(m), $1625(\mathrm{~s})$, $1562(\mathrm{~s}), 1456(\mathrm{~m}), 1409(\mathrm{w}), 1103(\mathrm{w}), 1057(\mathrm{w}), 982(\mathrm{w}), 909(\mathrm{~m}), 862(\mathrm{w}), 769(\mathrm{~s}), 722(\mathrm{~m}), 693(\mathrm{w})$, $545(\mathrm{w})$. Compared with the $\mathrm{H}_{3} \mathrm{~L} \cdot \mathrm{HCl}$ ligand, the carboxylic groups in complex 1 are completely deprotonated to carboxylate anions as demonstrated by the disappearance of the characteristic peak carboxylic group of $1727 \mathrm{~cm}^{-1}$ (Figure 9).

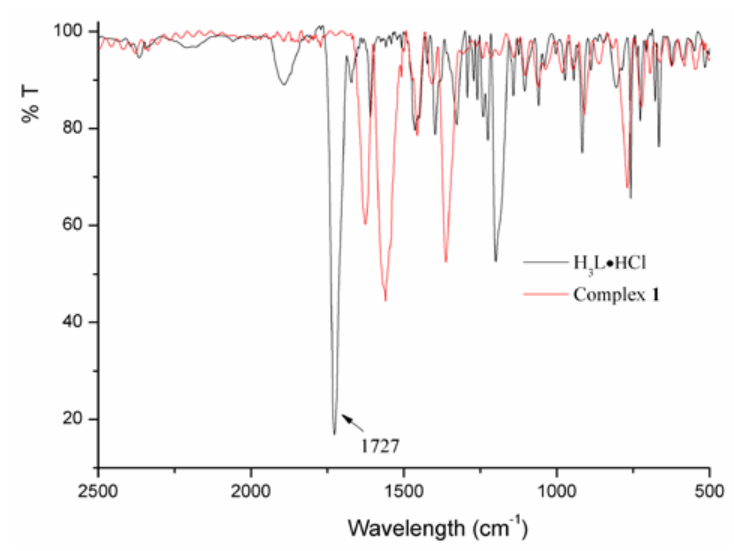

Figure 9. IR spectra of $\mathrm{H}_{3} \mathrm{~L} \cdot \mathrm{HCl}$ and complex 1.

\subsection{Crystal Structure Determination}

The single crystal data of $\left[\mathrm{Cu}_{4}(\mathrm{HL})_{4}\left(\mathrm{H}_{2} \mathrm{O}\right)_{14}\right](\mathbf{1})$ was collected on a Bruker Smart APEX CCD diffractometer with graphite-monochromated MoK $\alpha$ radiation $(\lambda=0.71073 \AA)$ at $293(2) \mathrm{K}$. The structure was solved by direct method and refined by full-matrix least squares on $\mathrm{F}^{2}$ using the SHELX-97 program [23]. The crystallographic data and structural refinements are listed in Table 3.

Table 3. Crystallographic data and structure refinements for $\mathbf{1}$.

\begin{tabular}{cc}
\hline Empirical Formula & $\mathbf{C}_{\mathbf{6 0}} \mathbf{H}_{\mathbf{8 8}} \mathbf{N}_{\mathbf{4}} \mathbf{O}_{38} \mathbf{C u}_{\mathbf{4}}$ \\
\hline Formula weight & 1727.50 \\
Temperature/K & $291(2)$ \\
Crystal system & Monoclinic \\
Space group & $C 2 / c$ \\
$a / \AA$ & $29.539(12)$ \\
\hline
\end{tabular}


Table 3. Cont.

\begin{tabular}{|c|c|}
\hline Empirical Formula & $\mathrm{C}_{60} \mathrm{H}_{88} \mathrm{~N}_{4} \mathrm{O}_{38} \mathrm{Cu}_{4}$ \\
\hline$b / \AA$ & $20.530(9)$ \\
\hline$c / \AA$ & $13.280(8)$ \\
\hline$\alpha /{ }^{\circ}$ & 90 \\
\hline$\beta /{ }^{\circ}$ & $95.365(9)$ \\
\hline$\gamma /{ }^{\circ}$ & 90 \\
\hline Volume $/ \AA^{3}$ & $8018(7)$ \\
\hline Z & 4 \\
\hline$\rho_{\text {calc }} \mathrm{mg} / \mathrm{mm}^{3}$ & 1.434 \\
\hline$\mu / \mathrm{mm}^{-1}$ & 1.136 \\
\hline S & 1.089 \\
\hline$F(000)$ & 3600 \\
\hline Index ranges & $-38 \leq h \leq 38,-26 \leq k \leq 22,-17 \leq l \leq 16$ \\
\hline Reflections collected & 36887 \\
\hline Independent reflections & 9546 \\
\hline Data/restraints/parameters & $9546 / 4 / 479$ \\
\hline Goodness-of-fit on $F^{2}$ & 1.021 \\
\hline Final $R$ indexes $[\mathrm{I}>=2 \sigma(I)]$ & $R_{1}=0.061, w R_{2}=0.1617$ \\
\hline Final $R$ indexes [all data] & $R_{1}=0.0985, w R_{2}=0.1694$ \\
\hline Largest diff. peak/hole/e $\AA^{-3}$ & $0.092 /-1.194$ \\
\hline
\end{tabular}

Crystallographic data for the structure reported in this paper has been deposited with the Cambridge Crystallographic Data Centre as supplementary publication No. CCDC 1572130 for 1. A copy of the data can be obtained free of charge on application to CCDC, 12 Union Road, Cambridge CB2 1EZ, UK (Fax: +44-1223-336-033; E-Mail: deposit@ccdc.cam.ac.uk).

\section{Conclusions}

In summary, we successfully obtained one new coordination polymer $\left[\mathrm{Cu}_{4}\left(\mathrm{HL}_{4}\left(\mathrm{H}_{2} \mathrm{O}\right)_{14}\right](\mathbf{1})\right.$ by the reaction of $\mathrm{Cu}$ (II) salt with a ligand with multicarboxylate functional groups. The complex shows a 1D chain structure. Furthermore, complex 1 exhibits water vapor adsorption properties.

Acknowledgments: This project was supported by the Natural Science Foundation of Fuyang (KJ2011B123) and the Key Projects of Support Program for Outstanding Young Talents in Anhui Province Colleges and Universities (gxyqZD2016068).

Author Contributions: Qiao Rui designed the method and completed the manuscript. Zhang Zi-You and Zhu Mei-An synthesized the ligand and the metal coordination polymers.

Conflicts of Interest: The authors declare no conflict of interest.

\section{References}

1. Long, J.R.; Yaghi, O.M. The pervasive chemistry of metal-organic frameworks. Chem. Soc. Rev. 2009, 38, 1213-1214. [CrossRef] [PubMed]

2. Almeida Paz, F.A.; Klinowski, J.; Vilela, S.M.F.; Tomé, J.P.C.; Cavaleiro, J.A.S.C.; Rocha, J. Ligand design for functional metal-organic frameworks. Chem. Soc. Rev. 2012, 41, 1088-1110. [CrossRef] [PubMed]

3. Chen, S.S.; Chen, M.; Takamizawa, S.; Wang, P.; Lv, G.C.; Sun, W.Y. Porous cobalt(II)-imidazolate supramolecular isomeric frameworks with selective gas sorption property. Chem. Commun. 2011, 47, 4902-4904. [CrossRef] [PubMed]

4. Miao, Z.; Luan, Y.; Qi, C.; Ramella, D. The synthesis of a bifunctional copper metal organic framework and its application in the aerobic oxidation/Knoevenagel condensation sequential reaction. Dalton Trans. 2016, 45, 13917-13924. [CrossRef] [PubMed]

5. Chen, S.S. The roles of imidazole ligands in coordination supramolecular systems. CrystEngComm 2016, 18, 6543-6565. [CrossRef] 
6. Fang, W.H.; Zhang, L.; Zhang, J.; Yang, G.Y. Halogen dependent symmetry change in two series of wheel cluster organic frameworks built from $\mathrm{La}_{18}$ tertiary building units. Chem. Commun. 2016, 52, 1455-1457. [CrossRef] [PubMed]

7. Ren, G.J.; Chang, Z.; Xu, J.; Hu, Z.; Liu, Y.Q.; Xu, Y.L.; Bu, X.H. Construction of a polyhedron decorated MOF with a unique network through the combination of two classic secondary building units. Chem. Commun. 2016, 52, 2079-2082. [CrossRef] [PubMed]

8. Chen, S.S.; Sheng, L.Q.; Zhao, Y.; Liu, Z.D.; Qiao, R.; Yang, S. Syntheses, structures, and properties of a series of polyazaheteroaromatic core-based $\mathrm{Zn}$ (II) coordination polymers together with carboxylate auxiliary ligands. Cryst. Growth Des. 2016, 16, 229-241. [CrossRef]

9. Mihaly, J.J.; Zeller, M.; Genna, D.T. Ion-directed synthesis of indium-derived 2,5-thiophenedicarboxylate metal-organic frameworks: Tuning framework dimensionality. Cryst. Growth Des. 2016, 16, 1550-1558. [CrossRef]

10. Hua, J.A.; Zhao, Y.; Kang, Y.S.; Lu, Y.; Sun, W.Y. Solvent-dependent zinc(II) coordination polymers with mixed ligands: Selective sorption and fluorescence sensing. Dalton Trans. 2015, 44, 11524-11532. [CrossRef] [PubMed]

11. Kamari, A.A.; Haque, R.A.; Razali, M.R. A heterobimetallic 2-D coordination polymer $\left[\mathrm{Na}_{2}\left(\mathrm{Cu}_{2} \mathrm{I}_{2}(2 \mathrm{pyCOO})_{4}\right)\right.$ $\left.\left(\mathrm{H}_{2} \mathrm{O}\right)_{4}\right]_{\mathrm{n}}\left(2 \mathrm{pyCOO}^{-}=\right.$picolinate $)$within a 3-D supramolecular architecture. Crystals 2016, 6, 96. [CrossRef]

12. Zhu, M.A.; Guo, X.Z.; Chen, S.S. Synthesis, Crystal Structure and Luminescent Property of a Zn(II) Complex Based on 4-Imidazole-carboxylate Ligand. Chin. J. Struct. Chem. 2017, 36, 1348-1354.

13. Suckert, S.; Germann, L.S.; Dinnebier, R.E.; Werner, J.; Näther, C. Synthesis, structures and properties of cobalt thiocyanate coordination compounds with 4-(hydroxymethyl)pyridine as Co-ligand. Crystals 2016, 6, 38. [CrossRef]

14. Zhang, Y.B.; Furukawa, H.; Ko, N.; Nie, W.; Park, H.J.; Okajima, S.; Cordova, K.E.; Deng, H.; Kim, J.; Yaghi, O.M. Introduction of functionality, selection of topology, and enhancement of gas adsorption in multivariate metal-organic framework-177. J. Am. Chem. Soc. 2015, 137, 2641-2650. [CrossRef] [PubMed]

15. Chen, S.S.; Liu, Q.; Zhao, Y.; Qiao, R.; Sheng, L.Q.; Liu, Z.D.; Yang, S.; Song, C.F. New metal-organic frameworks constructed from the 4-imidazole-carboxylate ligand: Structural diversities, luminescence, and gas adsorption properties. Cryst. Growth Des. 2014, 14, 3727-3741. [CrossRef]

16. Zhang, Z.Y.; Xiao, L.; Chen, S.S.; Qiao, R.; Yang, S. A novel Zn(II) complex with 4-connected umc topology: Synthesis, crystal structure and luminescent property. Chin. J. Struct. Chem. 2017, 36, 819-824.

17. Chen, S.S.; Qiao, R.; Sheng, L.Q.; Zhao, Y.; Yang, S.; Chen, M.M.; Liu, Z.D.; Wang, D.H. Cadmium(II) and zinc(II) complexes with rigid 1-(1H-imidazol-4-yl)-3-(4H-tetrazol-5-yl)benzene and varied carboxylate ligands. CrystEngComm 2013, 15, 5713-5725. [CrossRef]

18. Xiao, L.; Li, W.D.; Fang, X.; Jiang, L.Y.; Chen, S.S. Two three-dimensional supramolecular polymer built from mixed N-donor and carboxylate ligands. Chin. J. Struct. Chem. 2016, 35, 781-788.

19. Qiao, R.; Chen, S.S.; Sheng, L.Q.; Yang, S.; Li, W.D. Syntheses, crystal structures, and properties of four complexes based on polycarboxylate and imidazole ligands. J Solid State Chem. 2015, 228, 199-207. [CrossRef]

20. Li, W.D.; Fang, X.; Qiao, R.; Chen, S.S. Non-covalent bonded 3D supramolecular architectures based on acid-base adducts. Chin. J. Struct. Chem. 2016, 35, 46-54.

21. Spek, A.L. Single-Crystal Structure Validation with the program PLATON. J. Appl. Crystallogr. 2003, 36, 7-13. [CrossRef]

22. Li, Y.L.; Hua, J.A.; Zhao, Y.; Kang, Y.S.; Sun, W.Y. Metal-organic frameworks with 1,3,5-tris(1-imidazolyl)benzene and dicarboxylate ligands: Synthesis, anion exchange and gas adsorption. Microporous Mesoporous Mater. 2015, 214, 188-194. [CrossRef]

23. Sheldrick, G.M. A short history of SHELX. Acta Cryst. 2008, A64, 112-122. [CrossRef] [PubMed]

(C) 2017 by the authors. Licensee MDPI, Basel, Switzerland. This article is an open access article distributed under the terms and conditions of the Creative Commons Attribution (CC BY) license (http://creativecommons.org/licenses/by/4.0/). 